geldwezen en industric van invloed zijn op ons beroep en op de uitocfening daarvan.

Fn misschien moest aan het examen voor het verkrijgen van het accountants-diploma worden toegevoegd als letter „E'" een bezock aan de Tereenigde Staten van Noord-Amerika.

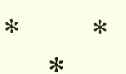

Remarks of $M_{r} \cdot$ E. van Dien at general sessions on T'uesday, October 19th, 1938

This is the third conference of American accountants I have had the pleasure and the honor to address. The first was, as your Chairman has said, in $1904 \mathrm{in}$ St. Louis, during the World's Fair. There were some other's present at that time in St. Louis, and I am told by your Secretary cleven of these are still here today. I am most happy to call their names: Mr Harvey S. Chase, Mr. J. B. Gooduin, Mr David L. Grey, Mr E. G. II. Tessler, Mr Willian MI. Lybrand, Mr George O. May, $\mathrm{Mr}$ Robert H. Montgomery, Mr John B. Wiven, Mr Joseph M. Pugh, $\mathrm{Mr}_{\mathrm{r}}$ Ernest lieckitt, and $\mathrm{Mr}^{\circ}$ Walter A. Staub.

Well, I hope, ladies and gentlemen, that I may meet these gentlemen again at the hundredth anniversary of the Institute of Certified ['ublic Accountants, and if it isn't here, it may be we will meet in heaven together.

Ladies and Gentlemen, in all these conferences I had the honor to represent my country and its Society, the Nederlandsch Instituut van Accountants, and today I bring the congratulations of all the accountants of the Society, being a Socicty of about 2.000 members, of whom 700 are fully qualified. I bring these greetings and the best wishes for the prosperity of the profession in the Trnited States, and I may add that from what I see and from what I learn and from what I read of your publications, your several monthly and quarterly papers, I am sure the American Institute of Certified Public Accountants is one of the leading Societies and one of the Societies that give direction to the profession in the right way.

Ladies and Gentlemen, this is an amiversary, and as I recall, anniversaries call for gifts, and I want to give a present to the American Institute of Accomtants. This is a sonvenir that I received in $190+$ at St. Louis with my dessert, and the finest dinner I ever had in my life at the Delmonico. It is a sriall bale of cotton. For thinty-three years I have had this on my desk before me. I never lost sight of it, and I protected it against the charwoman who wanted to clean it. 1 want to present this souvenir to the American Institute of Accountants on its 50th $\Lambda$ nniver'sary. I hope you will aceept it, and will keep it as a souvenir from a good triend.

I thank you.

E. VAN DIEN

\section{DE PLAATS VAN DEN RIJKSACCOUNTANTSDIENST IN DE ADMINISTRATIE DER BELASTINGEN}

Bij Koninklijk Besluit van 16 Augustus 1937 No. 49 werd met ingang van 1 September 1937 het Ambtenarenbesluit Belastingdienst gewijzigd, waurbij 0.m. de nam ,Accountantsdienst der directe belastingen', veranderd word in Rijksaccountantsdienst.

De accountants der directe belastingen zijn derhalve vanaf
Cat tijdstip geworden accountants, verbonden aan den Rijksaccountantsdienst, of kortweg rijksaccountants.

Door deze wijziging is thans formeel erkend, dat het arbeidsveld van deze accountants niet alleen ligt op het ter'rein der belastingen.

Historisch gezicn is hun functic begonnen met werkzaamherlen voor de controle der directe belastingen. Geleidelijk is men er toe overgegaan hun werkzammeden op het gebied der indirecte belastingen op te dragen. Doch claar is het niet bij gebleven; sinds een aantal jaren heeft men hen belast met opdrachten liggende buiten het terrein der belastingen. Dit kon zonder enig bezwar, omdat voor benoeming tot rijksaccountant zij atan dezelfde cischen moesten voldoen als voor publicaccountants zouden gelden. ZZoo zijn ze belast geworden met (le contrôle van overeenkomsten tusschen den Staat en derden, met de controle van noodijdende gemeenten, met opdrachten roor Rechtbanken in strafzalien, zijn ze toegevoegd aan Staatsof interdepartementale commissies enz. Al blijft weliswaar een belangrijk deel van hun arbeidsveld het terrein der belastingen, duidelijk is dat dit nict meer het eenigste terrein humner werkzaamheden is.

Zicdaar de vcrklaring van den naam Rijksaccountantsdienst en niet van Accountantsclienst der belastingen, zooals men wellicht anders gegeven zou hebben bij de gemelde namsverandering.

Waar velen nooit scherp de plaats ran den rijiksaccountant in de organisatie van den belastingdienst zien, leek het mịj goed van deze gelegenheid gebruik te maken om nog cens in groote lijnen een schets dier organisatie te geven.

Aan het hoofd van de administratie der belastingen staat, onder de bevelen van den Minister van Financiën, een directeur-generaal.

Aan dezen zijn Inspecteurs voor bijzondere diensten toegevoegd; de Inspecteur van den Rijksaccountantsdienst, bclast mot het toeziclit op de burcaux van dien dienst, is één van die functionarissen.

De administratie der belastingen valt in tweeën uiteen n.l. de administratio der dircete belastingen, invoerlechten en aceijnzen en de administratic der registratic. Net de leiding zijn distrietsgewịze belast directenren der directe belastingen, inv. en ace. of directeuren der registratic, terwijl ook sinds 1 Sept. 1.l. mogelijk is voor een bepald district een gemeenschappelijke directeur' ran 's Rijks Belastingen aan te wijzen. Niet onwaarschijnlijk is lat dit latste in de toekomst regel zal worden, hetgeen me uit een oogpunt van goede organisatie juist voorkomt.

Onder directe belastingen, invoerrechten en accijnzen ressortecren versehillende dicnsten:

1. Algemene Dienst, w.o. de belastingen naar inkomen en vermogen, dividend en tantièmebelasting, couponbelasting, doode-hand belasting vallen.

2. Dienst der invoerrechten en accijnzen w.o. de tariefwet, de wet op de omzetbelasting alsmede diverse aceijnswetten op godistilleerd, suiker, geslacht enz. vallon.

3. Dienst der grondbelasting.

4. Rijksaccountantsdienst.

5. Dienst van de wanrborg en de belastingen der gouden en zilveren werken.

6. Laboratorium van het departement van Financiën.

Onder l'egistratic ressorteeren diensten belast met de uitvocring vall :

1. Registratiewet. 
2. Successicwet.

3. Zegelwet.

Voorts :

4. Inspectios der domeinen.

5. Bewarders van hypotheken, kadaster en scheepsbewijzen.

6. Ingenieurs-verificateur', landmeters e.d. Fortom de meetkundige dienst van het kadaster.

7. Staatsloterij.

Elk dezel diensten heeft cen eigen staf van personeel.

Duidelijk blijkt nit deze opstelling dat de Rijksarecountantsdienst op één lijn met de overige diensten staat, m.a.w. niet ondergeschilit is a an cenigen anderen dienst.

Dit is zeer gelukkig omdat door deze onafhankolijkheid het personeel van dien dienst volkonen objectief ziju kan bij do uitrocring ran hal tak.

Zeker, men zal zich bewust zijn dat men de belangen van den Staat moet behartigen, doch dit behooft niet in te sluiten eenzijdighcid bij ziju optreden. De rijjksaecountantscienst heeft een advisecrende en/of rontroleerende tagk te verrichten.

On cen gocde samenwerking tusselien den rijksaccountant en de functionalissen belast met de uitrocring der diverse wetten te brvorderen, zịn uiteraard door het l.opartement instrueties uitgevaardigd, welke - ik wil dit hier nog ecus nadrukkelijk verklaren! - in geen cnkel opzicht de vrijheid van den rijksaccountant ten opzichte van de hem voorgelegde problemen ook maar cenigszins beperken.

Het rapport kan dan ook geheel "rolgens eer en geweten" worden uitgebracht.

\section{W. N. DH BLAFY}

\section{FISCUS EN LEVENSVERZEKERING}

Het voorschrift van art. 10, laatste lid ran de wet op de Inkomstenbelasting, luidencie:

,Traktementen en andere belooningen alsmede verlot- en non-activiteitstraktementen, wachtgelden en pensioenen worden verminderd met verplichte bijdragen voor pensioenen en fondsen',

heeft in het laatste tiental jaren andeiding gegeven tot een rrịj omvangrijke jurisprudentie, betreffende de vratg, welko bijdragen als ,verplichte" bijdragen kumnen worden beschouwd ch wat onder "bijdrage voor een fonds" moet worden verstann. In den loop dezer jurisprudentie vormen de arresten van den IIoogen liaud van 13 Maart 193\% een mij]paal. De quintessens der roornaamste arresten aan dezen epochemachenden datum voorafgaande, kan als volgt getrokken worden:

1e. De premie door den werkgever betaald voor pensioensverzekcring van cen werknemer vormt een dcel van dicns salaris, evenals zulls met gratificaties het geval is. Ilet is daarbij onverschillig, of de werkgever de pensionneering zijner werknemers beschouwt als een vrijwillige sociale daad, dan wel als een juridische verplichting, dic hij te humnen opzichte heeft aanvaard. Indien de premie roor pensioensveryekering door cen werkgever wordt gedragen, moet de werknemer zijje salaris, verhoogd met de voor hem betaalde premie, als belastbaur inkomen aangeven. Betaalt de werknemer zelf de premie, dan mag hij het bedrag niet in mindering van zijn inkomen brengen.

2e. Aftrek der premie voor pensiocnsverzekcring van het inkomen van den werknemer is alleen dan toegelaten op grond van art. 10, laatste lid, in geval van ecn verplichte bijdrage. dus indien de werknemer door zijn werkgever wordt genood-
Zalakt eenig offer te brengen ten einde zijn dienstbetrekking te bekomen of te behouden.

3e. Evencens mogen in aftrek van het inkomen gebracht worden de verplichte bijdraycn aan een spar-of voorzieningsfonds op gu'ond, dat art. 10 I.B. zoowel het oog heeft op pensioen- als op spaarfondsen.

te. Indien de verplichting der uerknemers tot storting van cen zeker percentage van hun salaris of loon in een spaar- of vcolzieningsfonds gepaard gaat met eene al dan niet periodiek vastgclegde verplichting tot storting van den werkgever in hetrelfde fonds, mogen de werknomers allecn hun eigen verplichte bijdragen, nict die ran den werkgever; in mindering ran linu inkomicn brengen.

De fiscus heeft in het algemeen bovenstaande opvattingen van den Hoogen had alanvard, totdat in de verrassende arresten van 13Mar.t 19:5 deze adugelegenheid over een gebeel anderen boeg werd gegooid. In deze arresten heeft de Hooge Radd zeer uitvoerige principicele beschouwingen gewijd aan het laatste lid van alt. 10 I.B. in verband met de kwestie der pensioens- en liapitaalswerzekering. De overname der uitvoelige motivecring dezer alresten, zelfs in excerpt, zou te vee] plaatsruimte velgen, zoodat wij moeten volstaan met te releveren de ommekeer, die de bewuste arresten in den stand van zaken hebhen teweeggebracht. Wij hebben gezien, dat volgens de opvatting, anterieur aan de arresten van 13 Maart 1935, alleen bijdragen, waaltoe de werlinemer verplicht uas, in mindering gebracht mochten worden van diens inkomen, geenszins die van den werkgever, daar deze immers voor den werknemer geen offer betcekenden. Zelfs de bijgeschreven rente, welke als opbrengst van roerend kapitaal valt onder art. 6 der wet op de inkomstenbelasting, werd door den Hoogen Raad niet als een bijdlage aan het fonds beschouwd, op grond ,dat, zall cr van een bijdrage in den zin van het laatste lid van art. 10 sprake zijn, cenig offer moet worden gebracht, doch dat dit hicr niet het geval is, laar de belanghebhende bloot een voordeel heeft verkregen en behouden" (arresten van 19 NovemJer 1930, B.i.B. no. 4850 en 11 funi 1931, B.i.B. no. 4992).

De leden van cen pensioen- of spaarfonds hadden dus 1 . belasting te betalen over de geldswaarde van het bedrag, waarmede hun tegoed bij het fonds steeg zoowel door stortingen van hun werligever als door hijschrijving van rente, alleen niet ovel hun eigen stortingen. Na de arresten van 13 Maart 1935 evenwel, viclen noch de rente, noch de stortingen van den werligever onder de 1. helasting van den werknemer.

Ook ten aanzion der lapitaulsverzelieving moet een scheidingssijn worden getrokken tussehen den toestand vóor en na de arresten van den Hoogen Raad van 1.3 Maart 1935. Vóór dien datum werd gecn aftrek van de voor een kapitaalsverzekering betaalde premie op grond van art. 10 laatste lid toegestan, zolfs indien de werknemer door zijn werkgever tot deze verzokering was verplicht.

A fortion werd cen beroep in art. 10 laatste lid afgewezen, indien de werligever zich bij arbeidsovereenkomst had verplicht tot betaling van de premiën voor eene kapitaalsverzekering ten behoeve van zijn werknemer. De Hooge Raad heeft een dergelijk geval in hoogste instantie berecht in zijn arrest van 29 Malart 1933 (B. 54.03), warin geconcludeerd werd, dat art. 10. latste lid, I.13. niet toepasselijk is, in geval men te doen heeft met cen veraclicringscontract, krachtens hetwclk de verzekeJaar - cen levenswerzekeringsmatschappij — zich verbindt $\mathrm{om}$ op cen hepaald tijdstip of bij overlijden, een som ineens uit te keeren. De IJooge Raad was n.l. van oordeel, dat de in zulk geral te storten premie niet vormt cen bijdrage voor pensioen of in een fonds. Dit standpunt leek inderdaad, de 